\title{
Poisoning and pesticides
}

To the Editor: The review by the Tygerberg Poison Information Centre (TPIC) in the May $S A M J^{[1,2]}$ highlights valuable information about the public health importance of pesticides as a source of acute poisoning, particularly among children. The epidemic of poisoning of children related to informal sector sales of street pesticides such as aldicarb, a World Health Organization (WHO) class Ia carbamate and cholinesterase inhibitor, is particularly worrying, given the high toxicity of these products, mainly registered for agricultural uses, and the weak capacity of our health system to identify street pesticide poisonings, particularly from aldicarb. ${ }^{[3]}$ Not only is aldicarb poisoning often misdiagnosed as organophosphate intoxication, but there is very low awareness among health professionals that all forms of pesticide poisoning constitute a medical notifiable condition. ${ }^{[4]}$ Because of its toxicity, aldicarb was banned for any uses in 2012, yet its sale in the informal sector for rodent control is ongoing and widespread, not only in South Africa (SA) ${ }^{[3]}$

That there were no cases of occupational circumstances among the acute poisonings reported or phoned in to the TPIC or seen at the hospital is heartening. However, this finding may also reflect underreporting, as previously documented in $\mathrm{SA},{ }^{[5]}$ or under-diagnosis. For example, London reported a case of mass methyl bromide poisoning, mistakenly diagnosed by a local general practitioner as mass hysteria, among female workers in a local dried fruit factory some years ago. ${ }^{[6]}$ More recent evidence from Tanzania suggests that occupational poisonings are common, but rarely prompt attendance to health facilities because they are generally not severe and farmers who suffer symptoms self-treat, for example with ingestion of milk. ${ }^{[7]}$ The implication that occupational circumstances may be more common than first identified is supported by data showing that, over the period 2000 -2008, SA reported over 12000 cases of pesticide poisoning, many occupational in origin. ${ }^{[8]}$ Moreover, healthcare providers may under-estimate or completely miss the presence of occupational exposures underlying a suspected case.

The editorial by Verdoorn ${ }^{[0]}$ that accompanied the articles makes the misleading claim that 'the TPIC studies show beyond any doubt that pesticides are not the main agent in human poisoning ... and attributes pesticide poisoning to end-users who are 'highly irresponsible. In fact, the TPIC study stated clearly that ' ... pesticides were the most 
common group of non-drug-related exposures and the most common group of all exposures in the study $(18.3 \%)$... ? The TPIC authors made no inference about the behavioural determinants of poisoning, were very careful in identifying potential biases in their data that may limit such inferences, and called for a number of public health measures that would aid prevention - for example, restricting the way in which pesticide products are sold and distributed, irrespective of their uses. ${ }^{[1,2]}$

Irresponsibility, as suggested by Verdoorn, implies that: ( $i$ ) labels are present on all pesticide containers; (ii) end-users can read pesticide labels; (iii) end-users who are literate can understand the risk information; and (iv) that all end-users have access to the means to protect themselves from toxic exposures. All four conditions may be found wanting in SA..$^{[3-6]}$ Few farm workers are able to understand the precautionary information and symbols on pesticide labels, and many of their misinterpretations lead to potential health risks. ${ }^{[10]}$ If 'it is not the products that are to be blamed, but rather people with insufficient knowledge ... ${ }^{;[]]}$whose responsibility is it to ensure that the general population has the literacy levels (including scientific and risk literacy) to understand the information on these products? Irresponsibility on the part of the victims of poisoning and their families is an opinion we do not share, since much can be done from a programmatic and policy point of view to practise upstream prevention at source. Simply blaming victims of pesticide poisoning for their problems is neither good public practice nor evidence based.

Because use as recommended on the label cannot be ensured in the context of low literacy and poor enforcement, or in the absence of availability and use of personal protective equipment, the United Nations Food and Agricultural Organization and the WHO are actively encouraging the governments of developing countries not to register or re-register highly hazardous pesticides.

\section{Leslie London}

Hanna-Andrea Rother

Centre for Occupational and Environmental Health Research, University of Cape Town, South Africa

leslie.london@uct.ac.za

1. Veale DJH, Wium CA, Müller GJ. Toxicovigilance I: A survey of acute poisonings in South Africa based on Tygerberg Poison Information Centre data. S Afr Med J 2013;103(5):293-297. [http://dx.doi.org/10.7196/SAMJ.6647]

2. Veale DJH, Wium CA, Müller GJ. Toxicovigilance II: A survey of the spectrum of acute poisoning and current practices in the initial management of poisoning cases admitted to South African hospitals. S Afr Med J 2013(5);103:298-303. [http:// dx.doi.org/10.7196/SAMJ.6648]

3. Rother HA. Falling through the regulatory cracks: Street selling of pesticides and poisoning among urban youth in South Africa. Int J Occup Environ Health 2010;16(2):202-213. [http://dx.doi.org/10.1179/107735210799160264]

4. Rother HA. Improving poisoning diagnosis and surveillance of street pesticides. $S$ 4. Rother HA. Improving poisonin
Afr Med J 2012;102(6):485-488.

5. London L, Bailie R. Challenges for improving surveillance for pesticide poisoning: 5. London L, Bailie R. Challenges for improving surveillance for pesticide poisoning:
Policy implications for developing countries. Int J Epidemiol 2001;30(3):564-570. [http://dx.doi.org/10.1093/ije/30.3.564]

6. London L. Human rights, environmental justice, and the health of farm workers in South Africa. Int J Occup Environ Health 2003;9:59-68.

7. Lekei EE. Establishment of a comprehensive surveillance system for acute pesticide poisoning in Tanzania. PhD thesis, University of Cape Town, 2012.

8. National Department of Health. Number of Pesticide Poisoning Cases Reported by Province, 2000 - 2008, South Africa. Pretoria: National Department of Health, Epidemiology and Surveillance, 2008.

9. Verdoorn GH. Toxicovigilance: Experience of the Tygerberg Poison Information Centre in context. S Afr Med J 2013;103(5):288-289. [http://dx.doi.org/10.7196/SAMJ.6840]

10. Rother HA. South African farm workers' interpretation of risk assessment data expressed as pictograms on pesticide labels. Environ Res 2008;108(3):419-427. [http://dx.doi.org/10.1016/j.envres.2008.07.005] 